\title{
Attitude toward Desire for Implant Treatment in South Coastal Karnataka Population: A Short-term Epidemiological Survey
}

\author{
Aruna M Bhat, Krishna D Prasad, Deeksha Sharma, Rakshith Hegde
}

\section{ABSTRACT}

The purpose of this survey was to determine the awareness of dental implant as a treatment modality among the people of South Coastal Karnataka and their attitude and desire for implant treatment and also the various constraints in implant treatment.

Materials and methods: This was a questionnaire-based study carried out on 100 edentulous or partially edentulous subjects.

Results: The results were evaluated by Pearson Chi-square test.

Conclusion: It was seen that a large percentage of people were not aware of dental implant treatment. But when educated about it, they showed positive response toward it. Hence, ignorance remains the barrier between the need and utilization of advanced dental treatment modalities.

Keywords: Dental implant treatment, Attitude, Awareness, South coastal Karnataka population.

How to cite this article: Bhat AM, Prasad KD, Sharma D, Hegde R. Attitude toward Desire for Implant Treatment in South Coastal Karnataka Population: A Short-term Epidemiological Survey. Int J Oral Implantol Clin Res 2012;3(2):63-66.

\section{Source of support: Nil}

Conflict of interest: None declared

\section{INTRODUCTION}

The main role of prosthodontics is the rehabilitation of patients after loss of teeth and oral function. However, there are no generally accepted rules about how to estimate need, demand or utilization of prosthodontic services in most situations, since individual preferences play a very important role. ${ }^{1,2}$

Individuals with less education and low income tend to have poorer dental status because of poor finances and edentulism is often associated with poverty and deprivation. ${ }^{3}$

Hence, these individuals do not even consider treatments they know they cannot afford. ${ }^{4}$

Also, older individuals accustomed to their conventional dentures do not show interest in implant treatment. ${ }^{5}$

This can be attributed to the social and cultural surroundings where the discomfort and difficulties associated with dentures are accepted with resignation and without complaint and where ability to cope and adapt is promoted. ${ }^{6}$
However, with the advent of new technology more restorative options have become available thereby, changing the face of demand for prosthodontic treatment.

Among these implant treatment has come into focus, since it provides excellent long-term results in rehabilitation of partially or completely edentulous patients. ${ }^{4}$

Despite of the new available restorative options, it is observed that there are substantial barriers between both need and demand and between demand and utilization. ${ }^{7}$

This is possibly due to the lack of information and awareness among the people. Also the financial cost lays a question mark in the people who are aware about implants.

This study evaluates the attitude of people toward desire for implant treatment.

\section{METHODOLOGY}

The study was conducted on 100 edentulous or partially edentulous subjects reporting to AB Shetty Memorial Institute of Dental Sciences, Mangalore and its rural centers over a period of 2 to 3 weeks during the month of May 2010.

The participants were randomly selected from these centers and were assessed by a questionnaire to fulfill the following objectives:

- To determine age and sex of people willing for the treatment.

- To determine the awareness of implant-supported prosthesis as a new treatment modality among the South coastal Karnataka population.

- To determine the attitude of people toward the implant treatment.

- To determine the various constraints in implant treatment like age, finance, fear of surgery, etc.

The results were evaluated by Pearson Chi-square statistical analysis to determine correlation between the variables.

\section{RESULTS}

The subjects were categorized into various age groups as shown in Table 1. It was observed that out of the people surveyed, those who reported in maximum number belonged to the age group of 31 to 45 . People reporting the least belonged to the age group of above 60 years. 


\begin{tabular}{lcc}
\hline \multicolumn{3}{c}{ Table 1: Age group of people surveyed } \\
\hline Age group & Frequency & Percentage \\
\hline $19-30$ & 20 & 20.0 \\
$31-45$ & 37 & 37.0 \\
$46-60$ & 29 & 29.0 \\
Above 60 & 14 & 14.0 \\
\hline Total & 100 & 100.0 \\
\hline
\end{tabular}

It was seen that only $26 \%$ of people surveyed were aware about the implant treatment, whereas $74 \%$ had not known about it (Fig. 1). After basic dental implant information was provided, 59\% of people showed positive attitude for implant treatment.

It was inferred from the study that more number of males ( 72\%) showed a positive attitude toward implant treatment (Fig. 2). Pearson Chi-square test value is 6.986 with a highly significant correlation ( $\mathrm{p}$-value 0.008 ) between gender and attitude for implant treatment.

The study showed a definite positive attitude toward implant treatment among the younger population (19-30 years). People in age group 31 to 45 and 46 to 60 years also

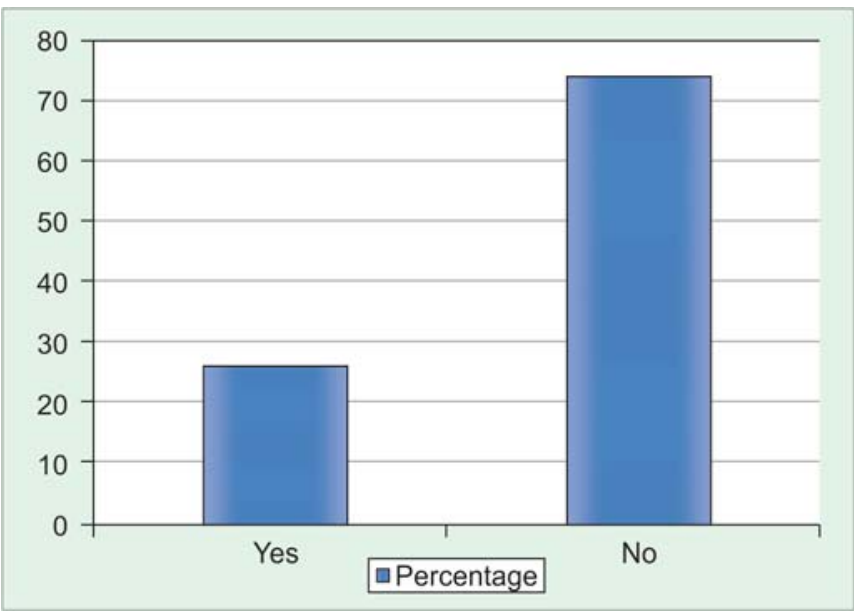

Fig. 1: Awareness of implant treatment

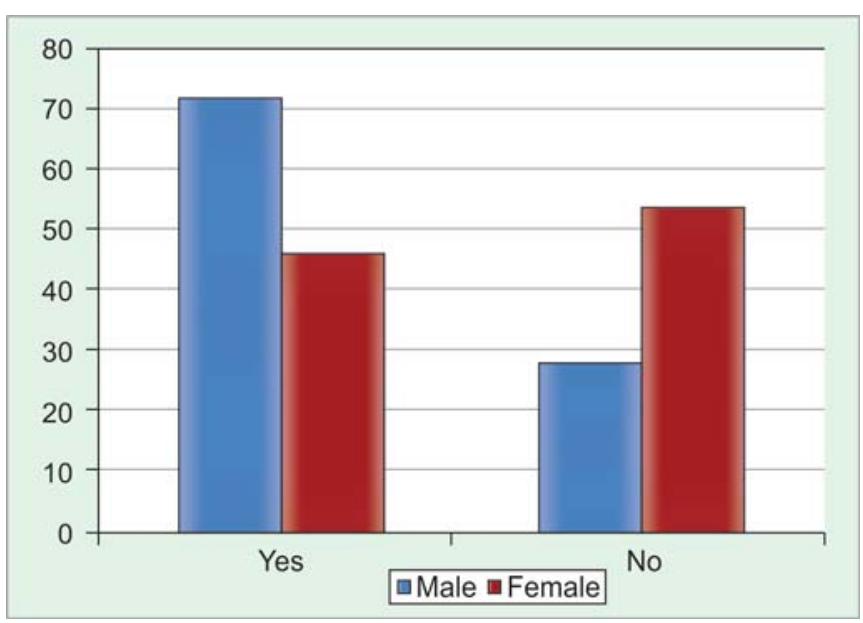

Fig. 2: Correlation between gender and attitude toward implant treatment showed increasing preference for implants (Fig. 3). However, the trend reversed as people crossed the age of 60 years. Pearson Chi-square test value is 7.271 with a nonsignificant ( $p$-value 0.064 ) correlation between age and attitude for implant treatment.

This study shows that females are more concerned about their esthetics while opting for implant treatment, while conversely males demand for function. Although overall percentage of female going for the treatment is lower than that of males. Pearson Chi-square test value is 9.572 and shows a highly significant (p-value 0.008) correlation between gender and reason for demand of implant treatment.

People who did not show interest in implants had various reasons to explain their negative attitude as depicted in Fig. 4. Financial restriction and fear of surgery together constituted for $70 \%$ of the constraints. Forty-six percent people anticipated to suffer from adaptability problems posttreatment. Advanced age proved to be the least common constraint out of all constraints. Also, large proportions of people $(78 \%)$ were not ready to undergo the treatment at the present moment but might consider it at a later stage.

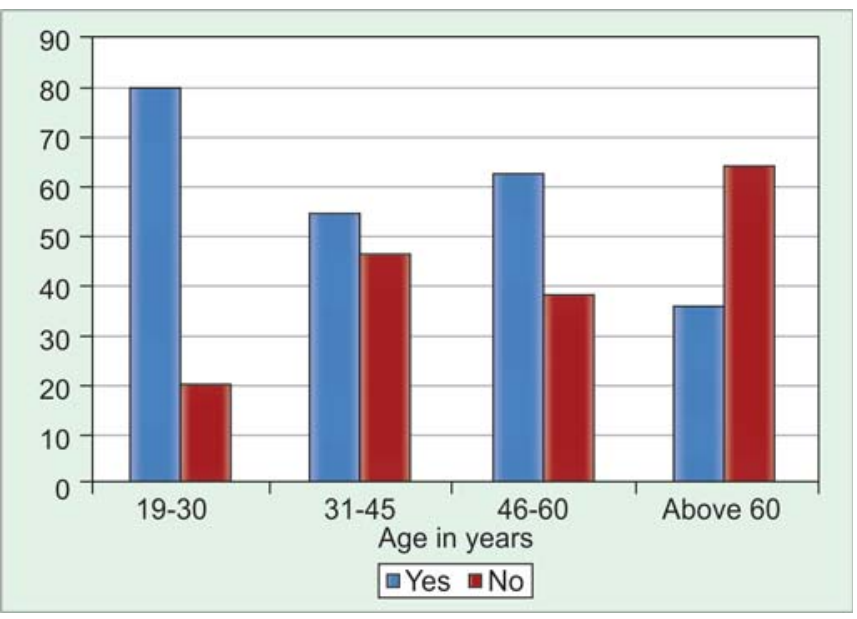

Fig. 3: Correlation between age and attitude toward implant treatment

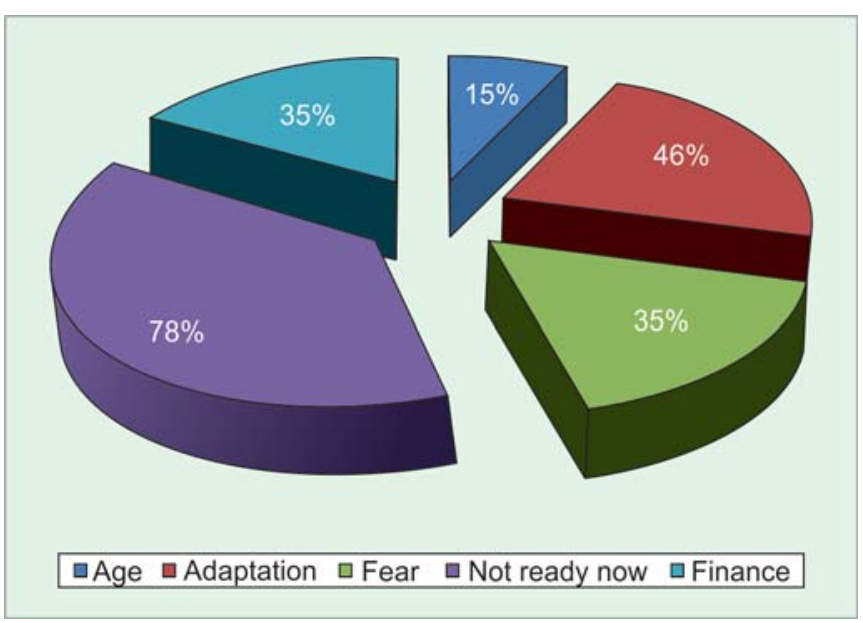

Fig. 4: Constraints 
Fear of surgery is seen to be more prevalent in females (50\%). Pearson Chi-square test gives a value of 7.494 with significant correlation (p-value 0.024 ) between gender and fear of surgery.

\section{DISCUSSION}

This study clearly projects the ignorance of the people toward dental treatment. These people do not seek dental consultation probably because they do not feel the need of doing so. This is in accordance with a study conducted on 65-year-old people in Ottawa to evaluate their oral status and treatment needs. ${ }^{8}$ Another study conducted in the urban population of India depicted the same scenario of negligence toward new advanced treatment modalities in dentistry. ${ }^{9}$

But it is observed that when this ice of ignorance is broken, people show positive responses toward dental care. In this study people were made aware of the implant technique, its merits and demerits. This dental education laid a great impact on the attitudes of the people and also made them aware of the recent treatment modalities.

It was noticed that after being educated many people showed positive attitude toward implant treatment. A similar kind of trend of showing positive attitude was seen in a longitudinal study done over a period of 10 years in Sweden. In this study, more number of people switched over to agreeing for implant treatment eventually. ${ }^{4}$

In this study a new aspect came into light. It is that males in South Coastal Karnataka are at a higher end in opting implant treatment over females. Esthetics is the preference in females, while males demand function when they choose implant as treatment modality.

Also, age showed variations in the choice of treatment. Younger population being enthusiastic and open to new advances opted this treatment modality in large numbers. Whereas toward the older end of the age spectrum choice for dental implants decreased. This can be due to various reasons, like loss of interest for change, acquaintance with old prosthesis, fear of surgery.

Maximum number of people who chose to reject the treatment modality stated that they were not ready for the treatment at present but might consider this option at a later stage. As anticipated, this treatment posed to be a financial load on many people but when asked about free treatment they agreed for the treatment. Hence, cost has remained the major barrier since the advent of implants. This has also been concluded in the longitudinal study discussed earlier. ${ }^{4}$

Also many people considered the possibility of facing problem in getting adapted to a new type of prosthesis. Other reasons for refusing the implant treatment were doubt about quality of life postsurgery, advanced age, lowered capacity to accept change.
Females being more vulnerable preferred to escape the implant surgery by refusing for the treatment. This attitude is also explained in a study done to evaluate the reasons for choosing or refusing dental implants. It is seen that most common and most highly rated reason for refusal was concern about surgical risks. However, anticipation of improved stability of mandibular denture was the most common reason for accepting implants. ${ }^{6}$

Hence, it can be concluded that awareness defines attitude. Proper dental education is necessary for developing positive attitude of people toward dental treatments.

\section{CONCLUSION}

Within the limitations of this study, it can be concluded that the people within age 30 showed maximum interest in the treatment in South Coastal Karnataka, whereas those above 60 did not consider the treatment for themselves.

This study shows the lack of awareness about dental implant treatment among the South Coastal Karnataka population. But people showed a positive attitude for dental implants when educated about it.

In the positive data, it is seen that males show a higher interest for the treatment than females and their expectation is improved function. On the contrary, females demand for esthetics over function.

There were many factors found to be responsible for not seeking implant treatment among which financial constraints and fear of surgery held a good percentage. Most of the people planned to go for implants after some time as they wanted to first assess its progress and then try it themselves.

\section{REFERENCES}

1. Narby B, Kronstrom M, Soderfeldt B. Prosthodontics and patient: A conceptual analysis of need and demand for prosthodontic treatment. Part I. Int J Prosthodont 2005;18: 75-79.

2. Beazoglou T, Brown LJ, Heffley D. Dental care utilization over time. Soc Sci Med 1993;37:1461-72.

3. Gratrix T, Holloway PJ. Factors of deprivation associated with dental caries in young children. Community Dental Health 1994; 11:66-70.

4. Narby B, Kronstrom M, Soderfeldt B. Changes in attitudes toward desire for implant treatment: A longitudinal study of a middle age and older Swedish population. Int J Prosthodont 2008;21:481-85.

5. Salonen MA. Assessment of states of dentures and interest in implant retained prosthetic treatment in 55-year-old edentulous Finns. Community Dental Oral Epidemiol 1994;22:130-35.

6. Joanne N Walton, Michael I MacEntee. Choosing or refusing oral implants: A prospective study of edentulous volunteers for a clinical trial. Int J Prosthodont 2005;18:483-88.

7. Narby B, Kronstrom M, Soderfeldt B. Prosthodontics and patient: Part II: Need becoming demand, demand becoming utilization. Int J Prosthodont 2007;20:183-89. 
8. Slade GD, Locker D, Wu ASM, Dunkley G. The oral health, status and treatment needs of adult aged 65 living independently in Ottawa- Carleton. Can J Public Health 1990;81:114-19.

9. Choudhary R, Mankani N, Chandraker NK. Awareness of dental implants as a treatment choice in urban Indian populations. Int J Oral Maxillofac Implants 2010; 25(2):305-08.

\section{ABOUT THE AUTHORS}

\section{Aruna M Bhat (Corresponding Author)}

Professor, Department of Prosthodontics, AB Shetty Memorial Institute of Dental Sciences, Mangalore, Karnataka, India, Phone: 09342014843, e-mail: drarunabhat3@yahoo.co.in

\section{Krishna D Prasad}

Professor and Head, Department of Prosthodontics, AB Shetty Memorial Institute of Dental Sciences, Mangalore, Karnataka, India

\section{Deeksha Sharma}

Postgraduate Student, Department of Prosthodontics, AB Shetty Memorial Institute of Dental Sciences, Mangalore, Karnataka, India

\section{Rakshith Hegde}

Reader, Department of Prosthodontics, AB Shetty Memorial Institute of Dental Sciences, Mangalore, Karnataka, India 